\title{
Inclusive Pedagogy and Universal Design Approaches for Diverse Learning Environments
}

\section{Catherine Shea Sanger}

Diversity presents an opportunity to foster deeper learning for our students and ourselves. The previous chapter argues that for diversity to result in substantial and equitable learning gains, it needs to go hand-inhand with intentional, widespread inclusion. At the same time, working to be inclusive of students who are diverse on multiple and intersecting dimensions can feel challenging and even overwhelming to many educators. Being deliberately inclusive in the classroom takes work, and not all faculty have a clear sense of where to start or expand their efforts in this area.

Building on these insights, this chapter introduces readers to two broad frameworks-Inclusive Pedagogy and Universal Design for Learningand eight specific strategies for promoting inclusion in diverse educational environments. The chapter is designed to be particularly useful to faculty who may be teaching outside their own cultural comfort zone, and those

C. S. Sanger $(\otimes)$

Yale-NUS College, Singapore, Singapore

e-mail: catherine.sanger@yale-nus.edu.sg

(C) The Author(s) 2020

C. S. Sanger and N. W. Gleason (eds.), 
who are teaching students who are very diverse in terms of nationality, ethnicity, communication style, and cultural context, as well as ability, socio-economic circumstance, and educational background. The strategies suggested here are drawn from evidence-based education, psychology, and neuroscience research; practice-based literature on pedagogy and teaching technique; as well as a decade of personal experience teaching, and supporting fellow teaching staff, across different learning environments.

The goal of this chapter is not to present cookie-cutter, all-purpose pedagogy. On the contrary, the goal is to share flexible instructional strategies that promote inclusivity across highly dissimilar contexts. By planning in advance for the multifaceted and vibrant diversity in your classrooms, and responding to student learning needs in an encompassing way, you can enhance inclusivity and teaching quality to the benefit of as many learners as possible.

\section{Inclusive Pedagogy and Universal Design FOR LEARNING}

Inclusive Pedagogy and the Universal Design for Learning framework offer practical tools and big-picture perspectives that help us harness student diversity for learning.

Inclusive Pedagogy is an approach that aims to make learning as accessible and welcoming to all students as possible. ${ }^{1}$ Some authors use the

\footnotetext{
${ }^{1}$ There are many practical guides on inclusive pedagogy, two of the most useful are Shari Saunders and Diana Kardia, Creating Inclusive College Classrooms (Ann Arbor: University of Michigan, 1994); "Guide to Inclusive Teaching at Columbia," Columbia University, accessed December 18, 2018, from https:// ctl.columbia.edu/resources-and-technology/inclusive-teaching-guide/. For more research and philosophical writing on the topic, see Barbara Gross Davis, Tools for Teaching, 2nd ed. (San Francisco: Wiley, 2009); Christine Hockings, "Inclusive Learning and Teaching in Higher Education: A Synthesis of Research," accessed December 18, 2018, from https://www.heacademy.ac.uk/knowledge-hub/inclusive-learningand-teaching-higher-education-synthesis-research; bell hooks, Teaching Community: A Pedagogy of Hope (New York: Routledge, 2003); Donald Mitchell, Charlana Simmons, and Lindsay Greyerhiehl, Intersectionality and Higher Education: Theory, Research, and Praxis (New York: Peter Land Publishing, 2014); Damon Williams, Strategic Diversity Leadership: Activating Change and Transformation in Higher Education (Sterling: Stylus, 2013).
} 
term 'inclusive pedagogy' primarily in the context of racial, gender, cultural, and socio-economic diversity. ${ }^{2}$ Others used it in the context of differently abled or special-needs learners. ${ }^{3}$ Across these different applications, inclusive pedagogy offers a critique of what is sometimes called a 'deficit approach'. The deficit approach assumes or demands that disadvantaged or marginalized students put in extra effort and get any additional support they need beyond the classroom. By contrast, inclusive pedagogy seeks to embed equitable access and opportunity for success within the classroom and curriculum. As articulated by Florian and BlackHawkins, inclusive pedagogy is underpinned by a shift in pedagogical thinking from an approach that works for most learners existing alongside something "additional" or "different" for those (some) who experience difficulties, towards one that involves providing rich learning opportunities that are sufficiently made available for everyone, so that all learners are able to participate in classroom life'. ${ }^{4}$

Although the term inclusive pedagogy has sometimes been applied to specific learner identities or dimensions of diversity, it is applicable across very different types of students and classrooms. From this more encompassing perspective, students with more and less normative cognitive abilities should have full access to course materials, just as students from more and less-resourced secondary schools should have equal understanding of their professors' assessment criteria. For this reason, inclusive pedagogy literature emphasizes equitable access to course materials and the importance of professors being transparent about their expectations of students.

Central to the concept of inclusive pedagogy is belonging, and research showing that feelings of belonging promote student engagement and learning. ${ }^{5}$ We promote a sense of belonging when we select topics, authors, assignments, and activities with student diversity in mind. We

\footnotetext{
${ }^{2}$ On inclusive pedagogy from a race and gender perspective see Hockings, "Inclusive Learning and Teaching."

${ }^{3}$ On inclusive pedagogy in terms of ability/disability see Leda Kamenopoulou, ed., Inclusive Education and Disability in the Global South (New York: Palgrave, 2018); L. Florian and K. Black-Hawkins, "Exploring Inclusive Pedagogy," British Educational Research Journal 37, no. 5 (2011): 813-828.

${ }^{4}$ Florian and Black-Hawkins, "Exploring Inclusive Pedagogy," 826.

${ }^{5}$ On the relationship between belonging, learning, and academic success see Terrell L. Strayhorn, College Students' Sense of Belonging: A Key to Educational Success for All Students, 2nd ed. (New York: Routledge, 2018); Laura D. Pittman and Adeya Richmond, "Academic and Psychological Functioning in Late Adolescence: The Importance
} 
teach students to engage with each other rigorously and with respect when we deliberately articulate class expectations and discussion guidelines. We also instil a sense of belonging when we humble ourselves enough as faculty to solicit student feedback and input as the class unfolds. These actions signal the professor's enthusiasm for the diversity in their class and desire to support all students' learning experience.

Universal Design for Learning (UDL) is similarly a framework that is broadly inclusive, without being hyper-individualized. The concept of UDL was elaborated and popularized by the Center for Applied Special Technology (CAST) in the 1990s and has subsequently become widely disseminated. As conceptualized by CAST, UDL encourages educators to provide: (1) multiple means of engagement-the 'Why' of learning; (2) multiple means of representation - the 'What' of learning; and (3) multiple means of action and expression-the 'How' of learning. ${ }^{6}$

The notion of UDL, as articulated by long-time proponent Sheryl Burgstahler, is 'to maximize the learning of students with a wide range of characteristics by applying UD principles to all aspects of instruction

of School Belonging," The Journal of Experimental Education 75, no. 4 (2007): 270290; Joan M. Ostrove and Susan M. Long, "Social Class and Belonging: Implications for College Adjustment," The Review of Higher Education 30, no. 4 (2007): 363-389; L. R. M. Hausmann, J. W. Schofield, and R. L. Woods, "Sense of Belonging as a Predictor of Intentions to Persist Among African American and White First-Year College Students," Research in Higher Education 48, no. 7 (2007): 803-839; P. Yi, "Institutional Climate and Student Departure: A Multinomial Multilevel Modeling Approach," Review of Higher Education 31, no. 2 (2008): 161-183; Isabel Moallem, "A Meta-Analysis of School Belonging and Academic Success and Persistence" (PhD diss., Loyola University Chicago, 2013), 726; S. J. Spencer, C. M. Steele, and D. M. Quinn, "Stereotype Threat and Women's Math Performance," Journal of Experimental Social Psychology 35 (1999): 4-28; J. Aronson and M. Inzlicht, "The Ups and Downs of Attributional Ambiguity: Stereotype Vulnerability and the Academic Self-Knowledge of African-American Students," Psychological Science 15, no. 12 (2004): 829-836; J. Aronson, C. Fried, and C. Good, "Reducing the Effects of Stereotype Threat on African American College Students by Shaping Theories of Intelligence," Journal of Experimental Social Psychology 38 (2002): $113-125$.

6 "The UDL Guidelines," CAST, udlguidelines.cast.org. See also Thomas J. Tobin and Kirsten T. Behling, Reach Everyone, Teach Everyone: Universal Design for Learning in Higher Education (West Virginia University Press, 2018); Jeanne L. Higbee and Emily Goff, eds., Pedagogy and Student Services for Institutional Transformation: Implementing Universal Design in Higher Education (Minneapolis: University of Minnesota, 2008); Sheryl E. Burgstahler, ed., Universal Design in Higher Education: From Principles to Practice, 2nd ed. (Cambridge: Harvard Education Press, 2015). 
(e.g., delivery methods, physical spaces, information resources, technology, personal interactions, assessments)'. 7 Rather than waiting to learn that a specific student needs additional or specialized support, the UDL approach encourages educators to plan their curriculum and pedagogy to anticipate broad diversity in student learning needs and proclivities. A UDL approach focuses less on the narrow accommodation of specific disabilities or identities, and more on a holistic approach to boosting everyone's learning.

UDL was initially focused on supporting students with varied learning abilities, but lends itself naturally to culturally diverse and international learning contexts. ${ }^{8}$ Most tactics that benefit one group or type of learners benefit others as well. For example, complementing verbal lectures with visual aids helps not only students who may have hearing impairment but also those who are unfamiliar with the professor's accent or vocabulary.

UDL is sometimes misunderstood as advocating hyper-individualized support. This is not the case. The idea behind UDL is not to apply resource-intensive 'spot treatments' for individual student needs. Instead, UDL integrates broader structural changes that make our classes more engaging and accessible for all, regardless of specific student needs or required accommodations.

To illustrate, a 'spot-treatment' approach for helping students with attention deficits or hearing impairments would be to provide a designated note-taker for each individual student who qualifies for assistance. UDL draws our attention to the fact that many other students would benefit from seeing their peers' notes, even if they do not have an official

${ }^{7}$ Sheryl Burgstahler, "Universal Design of Instruction (UDI): Definition, Principles, Guidelines, and Examples," https://www.washington.edu/doit/universal-designinstruction-udi-definition-principles-guidelines-and-examples.

${ }^{8}$ Sean Bracken and Katie Novak, eds., Transforming Higher Education Through Universal Design for Learning: An International Perspective (Routledge: New York, 2019); CAST, "CAST," accessed December 18, 2018, from www.cast.org; "UDL on Campus," Universal Design for Higher Learning in Education, udloncampus.cast.org; "Guide to Creating Accessible Presentations," The Digital Library Federation, accessed December 18, 2018, from www.diglib.org/forums/2016forum/guide-to-creating-accessiblepresentations/; David Rose, Wendy Harbour, Catherine Johnston, Samantha Daley, and Linda Abarbanell, "Universal Design for Postsecondary Education: Reflections on Principles and Their Application," Journal of Postsecondary Education and Disability 19, no. 2 (2004): 135-151; "UDL Center," National Center on Universal Design for Learning, accessed December 18, 2018, from www.udlcenter.org; "Web Accessibility Initiative," accessed December 18, 2018, from www.w3.org. 
'disability' or 'condition' that confers such an accommodation. For example, seeing peers' class notes would be useful for students who are new to the language of instruction, first-year students who are new to collegiate academic habits, or students who are new to the discipline being taught and therefore unfamiliar with the professor's jargon. Given this, a professor might create a low-stakes assignment where students sign-up for a week to be responsible for anonymously sharing their notes with the entire class. Such an assignment will help students who have difficulty taking their own notes, but has the added benefit of exposing all students to different note-taking methods, which could be an important academic skills-builder for the entire class.

There is compelling evidence that taking this holistic, UDL approach to student learning and integrating multiple modes of instruction enhances learning for all. Far from expecting professors to tailor lessons to each individual student and their perceived 'learning styles', new research emphasizes the importance of exposing all students to diverse formats and learning processes. Students may believe they learn best by listening or by using visual aids, but evidence suggests most students do not have a single 'learning style' and in fact learn best when exposed to a range of modalities and representations. ${ }^{9}$

An enthusiastically inclusive approach makes a difference for students in the quality of learning and their interest in learning. In the voice of one student, as reported by UDL practitioner James Lang:

What we don't want is to be made to feel like we are a burden to you because we have requested accommodations. Many of us already have this feeling that we're burdening you, and it really helps if you can treat us like you want us to be in your course. We're not asking for accommodations

${ }^{9}$ Dung C. Bui and Mark A. McDaniel, "Enhancing Learning During Lecture NoteTaking Using Outlines and Illustrative Diagrams," Journal of Applied Research in Memory and Cognition 4, no. 2 (2015): 129-135; Russell N. Carney and Joel R. Levin, "Pictorial Illustrations Still Improve Students' Learning from Text," Educational Psychology Review 14, no. 1 (2002): 5-26; Harold Pashler, Mark Mcdaniel, Doug Rohrer, and Robert Bjork, "Learning Styles: Concepts and Evidence," Psychological Science in the Public Interest 9, no. 3 (2008): 105-119; Youki Terada, "Multiple Intelligences Theory: Widely Used, Yet Misunderstood," October 15, 2018, https://www.edutopia.org/article/ multiple-intelligences-theory-widely-used-yet-misunderstood; F. Coffield, D. Moseley, E. Hall, and K. Ecclestone, Learning Styles and Pedagogy in Post-16 Learning: A Systematic and Critical Review (London: Learning and Skills Research Centre, 2004). 
to make your life difficult, or because we're trying to get away with something. We want to be in your course. We just need your help learning the best we can. ${ }^{10}$

\section{Strategies for Inclusive Teaching}

Teachers can apply the following strategies to diverse higher education settings in order to foster student belonging and learning. Consistent with UDL, the techniques offered here are not organized primarily around types of diversity or difference. Instead, most strategies promote learning and a sense of belonging across multiple dimensions of diversity.

\section{Proactively Learn About Your Environment, Especially Stu- dents' Prior Educational Contexts}

Following the UDL approach, instructors do not need to know each student's personal backstory to be an effective or inclusive teacher. However, especially when faculty are teaching outside their own cultural milieu, and do not have familiarity with their students' educational or social context, it is valuable to learn about the identities and backgrounds in your classroom. For example, when the author relocated from the United States to Singapore, it was important to learn that almost all Singaporean males do two years of National Service prior to attending university, a feature of local context that has implications for pedagogy, especially when teaching first-year students. There are a number of ways of acquiring information about your educational context, from reading up on local history to meeting with Admissions officers to inquire about student demographics and educational backgrounds.

Although UDL is geared towards creating broadly inclusive learning environments, inclusive pedagogy research tells us that students do appreciate having their individual identities and lived experiences acknowledged by professors. You can signal you care about students as individuals by surveying them prior to the start of the term to learn basic information like nationality, languages, prior education system, perceived learning preferences, preferred gender pronouns, etc. Gathering this information allows

${ }^{10}$ James M. Lang, “A Welcoming Classroom," September 27, 2017, https://www. chronicle.com/article/A-Welcoming-Classroom/241294. See also James M. Lang, Small Teaching: Everyday Lessons from the Science of Learning (New York: Jossey-Bass, 2016). 
you to acknowledge diversity in your class, and follow-up with individual students to make sure their needs are being met.

If you are working in a diverse context in terms of nationality and/or socio-economic background, there is likely to be a huge variety of students' prior educational experience in terms of curriculum, pedagogy, and norms of classroom engagement. ${ }^{11}$ Students may not understand why you are assigning a certain activity, or what you expect from essays, problem sets, or presentations. They may have never been asked to speak in class before, or to write an analytical essay. Giving students a way to communicate their prior knowledge, or lack thereof, can help you pitch your class appropriately. Inquiring about prior education also signals to students that you are aware of their diverse backgrounds and that you are looking forward to working with them to succeed in your class. ${ }^{12}$

As such, some inclusive pedagogical strategies do require knowledge about individual students. For example, the following strategies help leverage information about students' backgrounds to enhance learning:

- Meet individually with students and ask about their transition to college and prior educational experiences. Consider mandatory office hours appointments for first-year students. If you are teaching a large class, consider scheduled group office hours to get students accustomed to visiting you outside of class in small batches.

- Administer an anonymous intake survey or reflective writing activity to better understand the prior knowledge of your students. Share the information you received in anonymous form back with the students, which will help them see that while they may all have different personal histories, they probably share some common hopes and fears.

${ }^{11}$ Erin Meyer, The Culture Map: Decoding How People Think, Lead, and Get Things Done Across Cultures (New York: PublicAffairs, 2015); Nicolla Rolls, Andrew Norhedge, and Ellie Chambers, eds., Successful University Teaching in Times of Diversity (New York: Palgrave Teaching and Learning, 2018).

${ }^{12}$ Marlieke van Kesteren, Mark Rijpkema, Dirk J. Ruiter, Richard G. M. Morris, and Guillén Fernández, "Building on Prior Knowledge: Schema-Dependent Encoding Processes Relate to Academic Performance," Journal of Cognitive Neuroscience 26, no. 10 (2014): 2250-2261; Maryellen Weimer, Learner-Centered Teaching: Five Key Changes to Practice (New York: Jossey-Bass, 2013). 
- Give students an opportunity to share relevant personal information without forcing them to reveal information they prefer to keep private. For example, if you are teaching a smaller class, invite information but give students choice over what they share, e.g. 'Please share anything you would like us to know about your name, gender pronouns, educational background, learning needs, and learning goals'. (This approach depends heavily on local context. In an institution or country where being transgender is illegal or highly stigmatized, or where people with special learning needs are ostracized, you may not want to encourage students to share information that could make them vulnerable to violence or exclusion by peers or other professors.)

- When assigning group work activities, intentionally pair students with more and less prior experience so that the more experienced students can help guide their less experienced peers.

Additionally, the following techniques do not require information about specific students but can still contribute to making your classroom inclusive of students with differences in an educational context. ${ }^{13}$

${ }^{13}$ Many of these strategies are drawn from the following resources: Mary Brabeck, Jill Jeffery, and Sara Fry, "Practice for Knowledge Acquisition (Not Drill and Kill)," accessed December 18, 2018, from https://www.apa.org/education/k12/practice-acquisition. aspx; John Bransford, Ann Brown, and Rodney Cocking, "How Experts Differ from Novices," in How People Learn: Brain, Mind, Experience, and School, edited by Ann Brown, Rodney Cocking, M. Suzzanne Donovan, and James W. Pellegrino (Washington, DC: The National Academies Press, 2000), 31-50; Adam Persky and Jennifer Robinson, "Moving form Novice to Experts and its Implications for Instruction," American Journal of Pharmacentical Education 81, no. 9 (2017): 6065; "Strategies to Create an Inclusive Course," Iowa State University, accessed December 18, 2018, from http://www. celt.iastate.edu/wp-content/uploads/2015/10/StrategiestoCreateanInclusiveCourse.pdf; Jessy Ramey, "12 Evidence Based Teaching Strategies to Create a Productive and Inclusive Classroom Climate," accessed December 18, 2018, from https://my.chatham.edu/ documents/documentcenter/12\%20Evidence $\% 20$ Based $\% 20$ Teaching $\% 20$ Strategies $\% 20$ to\% 20Create\%20Productive\%20and\%20Inclusive\%20Classroom\%20Climate\%20.pdf; "Teaching Problem Solving," Vanderbilt University, accessed December 18, 2018, from https:// cft.vanderbilt.edu/guides-sub-pages/problem-solving/; "Facilitating Challenging Conversations in the Classroom," University of Washington in St. Louis, accessed December 18, 2018, from https://teachingcenter.wustl.edu/resources/inclusive-teaching-learning/ facilitating-challenging-conversations-in-the-classroom/. 
- Explicitly acknowledge the various degrees of prior exposure among students, and solicit a discussion of prior learning environments and comfort zones.

- Create reflective activities (discussions, writing activities, silent reflection) throughout the term that prompts students to think about how their prior knowledge has been amplified, disrupted, or applied in the class. These do not need to be graded or even collected by the instructor to have a learning benefit for the students.

- Consider how your speech includes or alienates. Ask yourself if you routinely use words or references that are likely to be alienating to students from different educational backgrounds than you are used to. For example, using a sophisticated vocabulary can help students expand their own linguistic repertoire, but using 'fancy', unfamiliar words can also serve to intimidate and hinder comprehension. If you tend to use more esoteric language, consider telling students at the beginning of the term that they should ask if you use words they do not know, or they should write it down and look the words up after class. You could even give students participation credit for identifying and looking-up new words used during class, which signals that you do not expect students to already know all the words you are using.

\section{Signal Your Confidence in the Potential of Each Student}

Communicating high standards, along with a clear commitment to helping students achieve those standards, signals that all students belong and have the capacity for growth in your class. You can encourage students who may be struggling in your class by sharing your own moments of academic difficulty. Additionally, following the work of Carol Dweck and colleagues Paul O'Keefe and Greg Walton, emphasize a 'growth mindset' that, with effort, people can generally become better and more invested at things that were previously very challenging or even uninteresting. ${ }^{14}$

${ }^{14}$ O'Keefe, Dweck, and Walton, "Having a Growth Mindset Makes It Easier to Develop New Interests," Harvard Business Review, September 10, 2018, https://hbr.org/2018/ 09/having-a-growth-mindset-makes-it-easier-to-develop-new-interests; O'Keefe, Dweck, and Walton, "Implicit Theories of Interest: Finding Your Passion or Developing It?," Psychological Science 29, no. 10 (2018): 1653-1664; Dweck, Mindset: The New Psychology of Success (New York: Ballantine Books, 2016); “Teaching a Growth Mindset," PERTS, 
Other scholars have similarly found that a positive sense of self, paired with supportive individuals, can help students achieve academic success. ${ }^{15}$

Here are some specific suggestions for encouraging effort and signaling confidence in your students' ability to learn.

- Share your own academic struggles and how you managed setbacks and times of uncertainty. Modelling that it is okay to be uncertain, and that learning is a process, may inspire students to be open with you about their struggles so you can help them learn.

- When you see students putting in effort, acknowledge and encourage it. This can be through verbal encouragement in the moment, or even an email after the fact (e.g. 'Hello Jin, I was really impressed with the patience and perseverance you showed today during the lab experiment. Your attitude sets an important example for the whole class. Keep up the effort and good work').

- Ask students to report not only their answers but also the process they took to arrive at those answers. Provide feedback on process as well as final product.

- Make it okay to be unsure. Signal that all students belong and can thrive in your class by suggesting resources that students with less prior knowledge of your discipline or teaching style can use to catch up over the first few weeks. Invite students to meet with you if they feel confused or are looking for additional resources.

\section{Transparency: Be Explicit About Expectations and Strategies for Success}

Many countries in Asia have experienced rapid economic and educational development over the last several decades. As a result, many university-age students today are experiencing a radically different higher

accessed December 18, 2018, from https://www.mindsetkit.org/topics/teaching-growthmindset.

${ }^{15}$ Jairo N. Fuertes, William E. Sedlacek, and William M. Liu, "Using the SAT and Noncognitive Variables to Predict the Grades and Retention of Asian American University Students," Measurement and Evaluation in Counseling and Development 27, no. 2 (1994): 74-84; Terence J. Tracey and William E. Sedlacek, "Prediction of College Graduation from Noncognitive Variables by Race," Measurement and Evaluation in Counseling and Development 19, no. 4 (1987): 177-184. 
education context and job market than what their parents encountered. In this sense, in many Asian contexts university students exhibit some of the qualities that typically get described as 'first-generation student' in a North American context. ${ }^{16}$ This is especially relevant for students enrolled in liberal arts or more novel curricular programmes that were not previously offered in the relevant country or region. In such environments, even students who come from well-educated and affluent families may be the first in their family to attend a liberal arts college where they will be expected to take courses across multiple subjects and actively participate during class discussion. ${ }^{17}$

${ }^{16}$ For more on the obstacles academic success sometimes facing first-generation students, see Terrell L. Strayhorn, "Factors Influencing the Academic Achievement of FirstGeneration College Students," NASPA Journal 43, no. 2 (2006): 82-111; Nicole M. Stephens, Stephanie A. Fryberg, Hazel Rose Markus, Camille S. Johnson, and Rebecca Covarrubias, "Unseen Disadvantage: How American Universities' Focus on Independence Undermines the Academic Performance of First-Generation College Students," Journal of Personality and Social Psychology 102, no. 6 (2012): 1178-1197; Daniel J. Almeida, Andrew M. Byrne, Rachel M. Smith, and Saul Ruiz, "How Relevant Is Grit? The Importance of Social Capital in First-Generation College Students' Academic Success," Journal of College Student Retention: Research, Theory \& Practice (2019); Thai-Huy Nguyen and Bach Mai Dolly Nguyen, "Is the 'First-Generation Student' Term Useful for Understanding Inequality? The Role of Intersectionality in Illuminating the Implications of an Accepted-Yet Unchallenged-Term," Review of Research in Education 42, no. 1 (2018): 146-176; Andrew J. McMurray and Darrin Sorrells, "Bridging the Gap: Reaching FirstGeneration Students in the Classroom," Journal of Instructional Psychology 36, no. 3 (2009): 210-214; Jeffery E. Aspelmeier, Michael M. Love, Lauren A. McGill, Ann N. Elliott, and Thomas W. Pierce, "Self-Esteem, Locus of Control, College Adjustment, and GPA Among First- and Continuing-Generation Students: A Moderator Model of Generational Status," Research in Higher Education 53, no. 7 (2012): 755-781; Ryan D. Padgett, Megan P. Johnson, and Ernest T. Pascarella, "First-Generation Undergraduate Students and the Impacts of the First Year of College: Additional Evidence," Journal of College Student Development 53, no. 2 (2012): 243-266.

${ }^{17}$ Carole J. Elliott and Michael Reynolds, "Participative Pedagogies, Group Work and the International Classroom: An Account of Students' and Tutors' Experiences," Studies in Higher Education 39, no. 2 (2014): 307-320; Yael Sharan, "Cooperative Learning: A Diversified Pedagogy for Diverse Classrooms," Intercultural Education 21, no. 3 (2010): 195-203.

Nguyen Phuong-Mai, “Culturally Appropriate Pedagogy: The Case of Group Learning in a Confucian Heritage Culture Context," Intercultural Education 17, no. 1 (2006): 119.

"Using Roles in Group Work," University of Washington in St. Louis, accessed December 18, 2018, from http://teachingcenter.wustl.edu/resources/teaching-methods/groupwork-in-class/using-roles-in-group-work/. Thank you to Malcolm Keating who has shared these methods with me and many colleagues at Yale-NUS. 
First-generation students, and those who come from very different educational environments from their new university, may be unfamiliar and even feel alienated by the subtle, 'unwritten rules' of higher education. ${ }^{18}$ Expectations around speaking up during class, publicly asking questions, attending office hours, asking friends to proofread papers, and admitting uncertainty to professors may feel particularly challenging. A combination of unfamiliarity, imposter syndrome, shame, and guilt can combine to make first-generation students less likely to take full advantage of academic and emotional support resources such as faculty office hours, tutoring programmes, advising services, and peer support. ${ }^{19}$

This sense of self-doubt and inferiority is compounded if students come from cultural contexts where it is considered weak or unbecoming to ask for help. In such contexts, students cannot get helpful advice from family and may feel they cannot reach out to peers or professors for assistance either. This can lead to feelings of isolation and discouragement.

"Examples of Discussion Guidelines," CRLT, accessed December 18, 2018, from http://www.crlt.umich.edu/examples-discussion-guidelines. Headings and guidelines in brackets are not from the University of Michigan and have been inserted by the author.

${ }^{18}$ Dan Berrett, "The Unwritten Rules of College," The Chronicle of Higher Education, September 21, 2015, https://www.chronicle.com/article/The-Unwritten-Rules-of/ 233245; Ben Galina, "Teaching First-Generation College Students," accessed December 18, 2018, https://cft.vanderbilt.edu/guides-sub-pages/teaching-first-generation-collegestudents/.

${ }^{19}$ Many of the practical pedagogical steps to support first-generation learners are drawn from and inspired by the following resources: Dan Berrett, "The Unwritten Rules of College"; Ben Dedman, "For First-Generation Students, It's All About the Support You Have," Association of American Colleges and Universities, September 2017, https://www.aacu.org/aacu-news/newsletter/2017/september/perspectives; Sarah L. Eddy, and Kelly A. Hogan, "Getting Under the Hood: How and for Whom Does Increasing Course Structure Work?," Life Sciences Education 13, no. 3 (2014): 453-468; Ben Galina, "Teaching First-Generation College Students"; Kelly Hogan and Viji Sathy. "Structuring the Classroom for Inclusive Teaching," accessed December 18, 2018, from https://cfe.unc.edu/initiatives/structuring-the-classroom-for-inclusiveteaching/; Institute for Higher Education Policy, Supporting First-Generation Students Through Classroom-Based Practices (Washington, DC: Institute for Higher Education Policy, 2012); "First Generation College Students," University of Colorado, accessed December 18, 2018, from http://www.ucdenver.edu/faculty_staff/faculty/center-for-facultydevelopment/resources/Teaching\%20resources/firstgen/Pages/default.aspx; Jessica Yorks, "When Parents Can't Help: How Can We support First-Generation College Students?," April 23, 2018, https://Gcci.uconn.edu/2018/04/23/when-parents-cant-help-how-canwe-support-first-generation-college-students/\#. 
This confluence of potentially alienating dynamics makes it important for faculty to proactively explain the rationale and strategies for success in their classes, and reiterate to students the resources that are available to help. For example, rather than just sharing your office hours' time and location, explain what office hours are designed for and how students can use this one-on-one time with you.

Success in college requires effort, but knowing where to focus that effort is not intuitive to all students. Being explicit with students about academic success strategies like closely reading the syllabus, doing outlines and drafts of essays, sample lab notes, and clarifying assignments with faculty during office hours can help.

Here are some more specific tactics for promoting transparency in your teaching.

\section{3a. Be Explicit About Your Expectations}

It may be obvious to you why you have given students a particular activity or assignment, and how it will be evaluated. But for some students, this is not at all clear. To make your classroom inclusive to all, apply the TILT (Transparency in Learning and Teaching) framework and try to be as transparent as possible with your students about what you are asking them to do, why you are asking them to do it (e.g. what will they learn from it), and how you will evaluate their work. ${ }^{20}$ You can also help students transition to college by being explicit about things like email etiquette and how you want them to present themselves in class.

\section{3b. Provide Advice, Promote Resources, and Self-Help Strategies}

Some faculty feel that giving explicit advice on how to do well gives an unfair advantage to lazy students because it provides a short-cut for students who would not take the time to figure out how to succeed on their own. From an inclusive pedagogy perspective, we worry even more about the risk that students from different cultural or educational backgrounds from their professor might learn less because they do not feel empowered to ask the professor for help, and do not understand how to

\footnotetext{
${ }^{20}$ For more information on the TILT framework and research visit https://tilthighered. com.
} 
succeed in class. Failing to coach students for success privileges students from a shared cultural and educational background or better-resourced secondary schools, not students who are inherently more hard working.

When possible provide examples of what you consider to be high quality or exemplary work and, very importantly, the process students can use for achieving those results. Professors sometimes worry that sharing examples will dampen student creativity or lead to copying. If those are concerns, make it clear to students that you will reward intellectual risk-taking and what constitutes productive versus unproductive forms of deviation from the disciplinary norm.

You can help students help themselves by actively encouraging them to take full advantage of all academic support resources including office hours, peers both in the class and out, tutoring, faculty advisors, librarians, counselling centres, etc. If you feel comfortable doing so, you may want to share an example of how you took advantage of such resources during your education or how you have seen it make a difference for other students.

3c. Consider Aspects of Your Course That Might Be Particularly NonIntuitive

Explain in detail why these expectations matter to you and why your students benefit from investing in those skills or knowledge. For example, as more and more universities are moving away from emphasizing rote learning and towards critical thinking and communication skills, inclass participation becomes a more important part of the learning experience. However, many students come from secondary school systems where students were not encouraged to speak during class. Some students come from educational contexts where the students' job is to listen and absorb knowledge, and the professors' job is to impart knowledge. In such educational environments, students ask questions, and professors give answers. If this has been your educational experience since birth it is not at all clear why, once you get to university, the professor would be asking the questions and expecting the students to answer! The value of learner-centric teaching is not intuitive for those inculcated with other educational norms. If you emphasize discussion and active student contributions, be explicit about what that looks like and how students can get better at it. 


\section{Use Varied Teaching Techniques and Formats}

Teaching students using different formats and types of learning activities will help reduce inadvertent bias and give all students opportunities to cultivate and demonstrate learning.

\section{4a. Integrate Verbal, Visual, and Textual Representations}

When designing lessons, consider what barriers might exist for different types of learners in accessing and processing information in your class. How would students with less familiarity with your language, cultural references, or pedagogy engage? How might students with vision impairment, or attention deficits encounter your class? For example:

- If your primary delivery method is visual, consider complementing that with verbal information. Provide verbal descriptions while projecting pictures, graphs, and charts and/or ask students to describe in words or in writing what they see and what it means. This will deepen all students' comprehension of the ideas you are trying to convey, and give them practice in visually processing information. And for students with vision impairment or who are unfamiliar with the representational formats of your discipline, listening to peers describe the visual materials will help them understand the content even if they cannot process it visually the same way as their peers.

- Conversely, if you often transmit information in pure lecture format, consider sharing the transcript of your lecture so that students who may have difficulty integrating verbal information can complement lectures with a written format. This would help students with low hearing or auditory processing disorders, but also those who may be unaccustomed to your accent or jargon in the course. Some faculty are concerned that sharing lecture notes will discourage lecture attendance. However, there are other methods that can be used to boost attendance like implementing low-stakes quizzes or integrating more interactive mid-lecture activities. Moreover, it may be a worthwhile trade-off to give students who really want to learn more ways of understanding the course material by sharing transcripts, even if that means some of the less-motivated students skip 
lecture. Some students may even be able to achieve adequate learning and perform well on assignments without attending lecture, in which case it may be reasonable to let them decide whether or not to attend. But if lecture adds considerable learning value independent of the transcript, then students who are motivated to succeed in the class should also remain motivated to attend. This author's approach is to prioritize making learning as accessible as possible for students who put in effort, over coercing attendance by students who do not value the lecture.

4b. Mix-Up Learning Activities and Modes of Expression

Incorporating different types of activities and teaching methods will make your classroom more inclusive of students with different prior experiences and learning strengths. ${ }^{21}$ Here are several formats that can be integrated into many types of courses.

- Lectures with visual aids like images, charts, graphs, or videos offer an effective combination of visual and auditory learning.

- Lectures with interactive tools like clickers and PollEverywhere prompt students to learn material by taking actions and making decisions, also enhancing student attention.

- Informal discussions of a prompt chosen by the professor or by the class help students think and learn by 'talking things out' and hearing differing perspectives across the class.

- Formal discussions are more structured presentations or debates that may be especially beneficial for students who prefer to develop a script and refine their ideas internally before speaking out loud.

- Small group or paired activities can feel safer or more productive spaces for intellectual exploration than whole-class discussions for some students, especially when students come from secondary

${ }^{21}$ Linda Suskie, Assessing Student Learning: A Common Sense Guide (New York: Wiley, 2018). 
education systems that emphasize collaborative work over speaking aloud during class. ${ }^{22}$

- Writing in real time on a chalk or white board by the professor or by students can enhance and clarify what is being said during a discussion. The writing could take many forms, such as lists, causal diagrams, or mind-maps.

- Writing in real time on an online discussion board projected on a screen creates opportunities for anonymous contributions, which might be useful if teaching students who are unfamiliar and lack confidence contributing verbally to in-class discussions.

- Reflective writing exercises, especially when they are not shared with peers, can serve as a private, more personal exercise to stimulate analysis and critical thinking, and allowing students to take intellectual risks without fear of 'sounding stupid'.

\section{4c. Encourage Peer-to-Peer Learning}

Creating student-to-student learning opportunities helps maximize the gains from a diverse classroom. Create class-time activities and assignments where peers can support each other and bring their different talents together for shared success. Some research has found that peer support is not only important for students' emotional and social transition to college but also a very important factor in academic success. ${ }^{23}$ Peer support is especially important for first-generation college students, who will often feel peer advice is more valuable than family advice on academic matters. ${ }^{24}$ Organize study groups or review sessions for all students, perhaps making attendance mandatory or incentivized. Explicitly creating space for

${ }^{22}$ Prem Ramburuth and John McCormick, "Learning Diversity in Higher Education: A Comparative Study of Asian International and Australian Students," Higher Education 42 , no. 3 (2001): 333-350.

${ }^{23}$ Chun-Mei Zhao and George D. Kuh, "Adding Value: Learning Communities and Student Engagement," Research in Higher Education 45, no. 2 (2004): 115-138.

${ }^{24}$ Jessica M. Dennis, Jean S. Phinney, and Lizette Ivy Chuateco, "The Role of Motivation, Parental Support, and Peer Support in the Academic Success of Ethnic Minority First-Generation College Students," Journal of College Student Development 46, no. 3 (2005): 223-236; R. Richardson and E. Skinner, "Helping First-Generation Minority Students Achieve Degrees," New Directions for Community Colleges 1992, no. 80 (1992): 29-43. 
student-to-student learning signals the importance of collaborating with peers in learning. There are many different approaches and formats that support peer-to-peer learning. ${ }^{25}$

- Think-Pair-Shares: Students are given a prompt to think and possibly write about, then paired with another student and asked to share what they came up with. This combination of individual and interactive processing activates different kinds of learning and can be a more comfortable way for students to express themselves verbally than speaking up during a whole-class discussion. These can be very short activities (1 minute to think, 2 minutes to share) or more drawn-out exercises. These work in large and small classes.

- Jigsaw Activities: For a particular session students are assigned to small groups A, B, and C, with each group given a different task or prompt for discussion. After completing the discussion/task, representatives from each group reconfigure themselves so that new groups are composed of at least one $\mathrm{A}$, one $\mathrm{B}$, and one $\mathrm{C}$ representative. They then share what they learned/produced in their initial groupings. This activity can occur during a single class meeting, or across more than one session.

- Research Exercises: Students can apply and extend course content by engaging in research activities with one or more partner, either in a single class session or over the course of several weeks.

- Field Trips/Experiential Learning Activities: The whole class or small groups can be assigned to venture into the 'field', be that a museum, estuary, or bus station. Pairing or grouping students across diverse identities and backgrounds can make these experiential learning activities more illuminating as students interpret and take actions across diverse lenses.

25 Claire Howell Major, Elizabeth F. Barkley, and K. Patricia Cross, Collaborative Learning Techniques: A Handbook for College Faculty (New York: Jossey-Bass, 2005); Wilbert McKeachie and Marilla Svinicki, McKeachie's Teaching Tips, 14th ed. (Belmont: Wadsworth Publishing, 2013); David A. Kolb, Experiential Learning: Experience as the Source of Learning and Development (New York: Pearson, 1984); Bridget Arend and James R. Davis, Facilitating Seven Ways of Learning: A Resource for More Purposeful, Effective, and Enjoyable College Teaching (New York: Stylus, 2012). 
- Problem-Based Learning: Students work in groups to solve a problem, one that often does not have only one possible answer or resolution. The groups must determine what they need to know and do in order to solve the problem, and members work together to implement a plan of action. Groups may work together over for a short or longer duration. ${ }^{26}$

- Team-Based Learning: When implementing TBL, the class is divided into intentionally diversified teams and members work together over the duration of the course, allowing the group to build capacity, trust, and collaborative skills. When creating teams, it may be advantageous to consider if certain students might feel isolated or overpowered by their peers. If there are students who are underrepresented in the class, for example if there are only two female students, you may want to put them in the same group so they can support each other. In TBL most class-time is dedicated to teamwork. Like PBL, in TBL students gain practice applying course content and skills to novel and complex problems. ${ }^{27}$

\section{Practice Inclusive Assessment Techniques}

To help students progress, you need to know how well they are understanding course material and whether they are gaining competency in relevant skills. Students from diverse educational backgrounds and cultural contexts may shine at different kinds of assessments, building confidence

${ }^{26}$ Cindy E. Hmelo-Silver, "Problem-Based Learning: What and How Do Students Learn?," Educational Psychology Review 16, no. 3 (2004): 235-266; John R. Savery, "Overview of Problem-Based Learning: Definition and Distinctions," The Interdisciplinary Journal of Problem-Based Learning 1, no. 1 (2006): 9-20; Barbara J. Duch, Susan E. Groh, and Deborah E. Allen, eds., The Power of Problem-Based Learning: A Practical "How To" for Teaching Undergraduate Courses in Any Discipline (New York: Stylus, 2001); José A. Amador, Libby Miles, and Calvin B. Peters, The Practice of Problem-Based Learning: A Guide to Implementing PBL in the College Classroom (New York: Jossey-Bass, 2006).

${ }^{27}$ Larry K. Michaelsen and Michael Sweet, "The Essential Elements of Team-Based Learning," New Directions for Teaching and Learning 2008, no. 116 (2008): 7-27; Larry K. Michaelsen, Arletta Bauman Knight, and L. Dee Fink, eds., Team-Based Learning: A Transformative Use of Small Groups in College Teaching (New York: Stylus, 2004). More information is available at the Team Based Learning Collaborative online at http://www. teambasedlearning.org/definition/. I am grateful to colleagues Dave Smith and Matt Stamps who have expanded my understanding of these teaching methods. 
that is important to learning. ${ }^{28}$ To avoid implicitly grading a student's background, rather than their learning in your class, it is essential to employ inclusive assessment designs. ${ }^{29}$

Collectively, the recommendations below support students with disabilities and health impediments, who may be unfamiliar with your discipline or pedagogy, and those from cultural and educational contexts that differ from your own.

\section{5a. Vary Assessment Formats}

Combining different modes of assessment can help you evaluate a wider range of student learning. One possibility is even to give students the option of how they want to demonstrate their learning-through oral presentations, written essays, or visual representations-or to give students the option to complement traditional essays or exams with more personalized submissions as well. Consider, for example, integrating a mix of the following formats.

- Written assignments in traditional academic formats such as descriptive or analytic essays.

- Written assignments in journalistic, fictional, creative, or other formats.

- Verbal presentations (individual or team-based).

- Visual presentations and representations (posters, videos, photographic displays-individual or team-based).

- Online discussion forums or blogs.

${ }^{28}$ Nguyen, "Culturally Appropriate Pedagogy"; Sharan, "Cooperative Learning”; David Killick, Internationalization and Diversity in Higher Education: Implications for Teaching, Learning, and Assessment (New York: Palgrave, 2017); Margery Ginsberg and Raymond Wlodkowski, Diversity and Motivation: Culturally Responsive Teaching in College (New York: Wiley, 2009); Darla K. Deardorff, "Assessing Intercultural Competence in Study Abroad Students," in Living and Studying Abroad: Research and Practice, edited by Michael Bryam and Feng Anwei (Clevedon: Multilingual Matters, 2006), 232-256.

29 "Articulate Your Learning Objectives," Eberly Center, accessed December 18, 2018, from www.cmu.edu/teaching/designteach/design/learningobjectives.htlm; Amy Lee, Robert Roch, Marta Shaw, and Rhiannon Williams, Engaging Diversity in Undergraduate Classrooms: A Pedagogy of Developing Intercultural Competence (San Francisco: Wiley, 2012); Stevens and Levi, Introduction to Rubrics; John Biggs, Teaching for Quality Learning at University, 2nd ed. (Maidenhead: Open University Press, 2003). 
5b. Don't Let the Grade Speak for Itself-Offer Direct, Constructive Feedback

Some faculty will assume that students understand why they did poorly on an assignment, or that they did poorly due to lack of effort. That is not always the case, especially if you are asking students to demonstrate and process learning in novel ways. Students who are unfamiliar with your pedagogy and discipline may not know how to improve upon the work they submitted. Feedback is an essential way to help them advance. Here are some suggestions to enhance the quality of your feedback when teaching in diverse contexts.

- Give honest, direct, and constructive feedback.

- Recommend concrete steps to improve their work.

- Provide feedback promptly so students improve across assignments, thereby building confidence and commitment to continued effort.

- Encourage students to come to your office hours for additional advice as needed.

- When they are available, direct students to additional resources such as tutoring, a writing centre, or library, rather than just saying 'this needs improvement'.

- Share an exemplar with the entire class, and have the class discuss in detail what makes that particular work so successful.

\section{5c. Recognize Possible Barriers to Intercultural Communication}

While being clear and honest in feedback, it is also important to consider your tone and how students from different cultures might receive feedback. Ways of communicating vary considerably across different national and sub-national cultures, and across different personalities. Some communicative styles are more direct, conflict-tolerant, and emotionally expressive while others are more indirect and less overtly emotional. Additionally, some cultures have clearly differentiated formal versus informal communicative modes (one for home, another for work) while 
others adopt an informal communication style in classroom or professional contexts. ${ }^{30}$ These differences in communication style can unintentionally impede faculty from giving students helpful feedback.

For example, faculty members with more conflict-tolerant communication styles than their students might be accustomed to directly disagreeing with or correcting students during a classroom exchange. But for students who are unaccustomed to direct disagreement, who come from cultures that emphasize 'saving face' during public interactions, they may interpret a professor's critique as 'my professor hates me' or 'I must be really stupid'.

Misunderstanding feedback across communication styles can also operate in reverse, for example, if students from more formal educational cultures have instructors with informal, 'friendly' styles of expression. In such a situation, a faculty member who tends to use an encouraging, supportive tone might inadvertently give their students the inaccurate impression they are doing well in the course. Students will subsequently feel betrayed when they get low grades. Explaining your cultural context and feedback style early in the term, and being as clear in feedback as possible, can help students accurately interpret your feedback.

\section{5d. Consider Untimed Exams}

Another method of inclusivity in assessment is to consider untimed exams. Exams are not just opportunities to demonstrate knowledge. The act of taking a test also contributes to learning. For this reason, we want testtaking to be as inclusive as possible, because we want learning to be as inclusive as possible. Two of the most common learning accommodations students receive are extra time on exams and the ability to take exams in private rooms. These accommodations are recommended for students with a range of testing constraints, including dyslexia, attention deficits, and anxiety. Moreover, the individuals who are formally granted learning accommodations are hardly the only students in your class who would be able to learn more and perform better if exams were untimed. Consider

${ }^{30}$ Mitchell R. Hammer, "The Intercultural Conflict Style Inventory: A Conceptual Framework and Measure of Intercultural Conflict Resolution Approaches," International Journal of Intercultural Relations 29, no. 6 (2005): 675-695; Stella Ting-Toomey and Leeva C. Chung, Understanding Intercultural Communication, 2nd ed. (Oxford: Oxford University Press, 2011). 
whether speed is an important skill you are trying to teach, and if so, whether you have taken the time to teach students how to fulfil your expectations quickly. If not, consider letting all students take their exams on their own time.

Admittedly, timed exams are convenient for faculty, as they do not need to proctor long exams or find a time all students can be in a room together for an extended period. It may be worth considering, then, whether your students can take the exam independently, at their own pace and in their own space. This approach has the added benefit of not using up valuable in-class time on testing.

\section{5e. Provide Opportunities for Do-Overs}

Students who come to study from different countries or under-resourced secondary schools may have less practice doing the kinds of assignments that are common at their new university. Consider giving all students the opportunity to submit drafts for peer review, or to redo their first assignment if it is disappointing. This is a way to incentivize students to take your feedback seriously, and signals your commitment to support your most hard-working students. For example, you might give students the opportunity to rewrite a mid-term essay or rerun an experiment for one-third of the original grade. If you primarily assess student learning through exams, consider having a second exam for those who want to try again, and tell students you will give them the average of the two exam scores. Another option is to let students write a reflective memo after receiving their assignment feedback, discussing what they achieved in the assignment, and where they went astray. Admittedly, providing these 'doovers' is a time-consuming practice for faculty, as it requires writing a new exam or grading a new submission. It may not be a realistic option for faculty who have big classes and high teaching loads. But finding ways to encourage students to integrate feedback, such as a small grade boost for simply submitting a revised version of an assignment, may be worthwhile even in large classes.

\section{5f. Minimize Unconscious Bias with Rubrics and Blind Grading}

Bias can sneak its way into grading and assessment despite our best intentions. We might have affection for a student who shares our hobbies or 
seems to be working very hard in our class. We might feel a particular loyalty to a student who has served as a research assistant, or who is especially helpful during lab clean-up. It is of course wonderful when faculty can develop special mentoring relationships with individual students, but assessment should be a bias-free indicator to the student and to the professor of whether learning is being accomplished.

One way to reduce the risk of bias in your grading practices is to use rubrics with transparent and stable evaluative criteria. The act of creating a rubric helps faculty be clear in their own minds about what they assessing. If you are teaching students with varied linguistic backgrounds, consider in particular how much you want the final grade to reflect writing clarity, organization, grammar, etc. Rubrics also promote transparency with students. If you worry that providing a rubric will result in boring, formulaic essays, reports, or presentations, you can add in 'bravery' bonus points to encourage creativity and bold arguments. (See Chapter 3 'Beyond Fairness and Consistency in Grading' for more information on designing rubrics.)

Another helpful practice is to remove students' names from their submissions to keep biases out of your grading practices. Some faculty like to know who they are grading so they can reward progress and hard work by students who may have struggled in the past. It may be safer to grade anonymously initially, and then subsequently take effort and trajectory into account as part of bonus points or participation grades.

\section{5g. Reflect on Whether You Are Grading New or Prior Knowledge}

Students from similar cultural and educational systems to their professor's may be performing better not because they have learned more in the class, but because they are conforming to norms of expression the professor finds familiar and therefore more desirable. To the extent that you want to reward learning and not prior training and privilege, you may need to be very explicit with students about your standards, and provide the resources to help students achieve those standards.

To that end, ask yourself whether you are grading what you yourself have taught, or if you are primarily grading students' prior knowledge and educational background. For example, consider how much you want to penalize a student's grade for poor essay organization if you have not provided any instruction on what constitutes a quality essay for your class. 
Similarly, if you require student presentations but do not offer guidance on what constitutes a good presentation, it may be unfair to significantly penalize a student for speaking too quickly or putting too much text on their slides. This is another reason why rubrics are helpful because they help professors determine and communicate to students what they are assessing and how much weight to give different components of an assignment.

\section{Avoid Projecting Your Professional Goals and Learning Prefer- ences on Students}

It is perfectly natural to extrapolate from our own experience when thinking about how to help students learn. Unfortunately, a professor's personal experience may not be terribly relevant or helpful for all students. Take some time to contemplate whether you have historically rewarded and favoured students who think like you, who share your learning or expression styles, and whether your pedagogy assumes students learn best the same way you do. These unconscious tendencies can disadvantage students with different learning styles, strengths, and educational backgrounds. For example, you may develop your own thoughts by 'talking things out' but other students may achieve greater insights and comprehension through free writing exercises. This is why it is so valuable to integrate many different formats of learning and assessment activities.

What worked for you during university is not necessarily helpful for your students. University professors are a rare breed, and are probably not representative in their interests or intellectual habits of most university students. Rather than projecting your own experience, inquire about how your course fits into students' larger educational path and development goals. Ask them about what has worked best for them in terms of teaching technique and learning style in the past. If you teach a large class, you can even ask these sorts of questions through an anonymous survey at the beginning of the term. These questions will help students reflect on their own learning preferences, which is productive for learning in and of itself.

Additionally, depending on the university type and context, recognize that many (probably most) students do not share your career goals. University faculty are extremely diverse in many ways, except one: almost all faculty members have attended graduate school, earned a doctorate 
or similar advanced degree, and taken up careers as university educators. Your students will pursue a much more diverse set of careers and postgraduate opportunities. Even if students currently aspire to be like you, ten years after they get their degree the economy and job market is likely to have shifted in unpredictable ways.

Consider whether your teaching is designed for students with varied life goals and career aims, or whether you are teaching primarily for future academics like yourself. For example, many faculty default to assigning research essays, but integrating other types of assignments like videos or posters can help develop students' communicative repertoires. Consider how you can design your courses in ways that will benefit students with more diverse career paths ahead.

\section{Represent Diversity in Syllabi and Course Content}

The goal of inclusive pedagogy is to centre multiple viewpoints and identities in your course. Especially if you are teaching students from different countries and cultural traditions, proactively diversifying your syllabus and course content will help students feel that they belong, which in turn will help them learn. ${ }^{31}$

\section{7a. Create Opportunities for Students to Draw on Personal Identities}

Students often appreciate having the opportunity to share their perspectives and background, but typically resent being expected to represent their entire country, continent, or race. This is especially the case for students from less-represented countries, who may be tired of answering

${ }^{31}$ On the value of, and strategies for, using diverse authors, examples, references see Davis, Tools for Teaching; Regan Gurung and Loraeto Prieto, eds., Getting Culture: Incorporating Diversity Across the Curriculum (New York: Stylus, 2009); Hockings, "Inclusive Learning and Teaching"; Lee, Roch, Shaw, and Williams, Engaging Diversity in Undergraduate Classsrooms; Sherrill Sellers, Jean Roberts, Levi Giovanetto, Katherine Friedrich, and Caroline Hammargren, Reaching All Students: A Resource for Teaching in STEM, 2nd ed. (Madison: CIRTL, 2007); Maha Bali and Steve Greenlaw, "Tips for Inclusive Teaching," Chronicle of Higher Education, September 12, 2016, https://www.chronicle.com/ blogs/profhacker/tips-for-inclusive-teaching/62747; Jason Barr, "Developing a Positive Classroom Climate" (paper, The IDEA Center, 2016); Ginsberg and Wlodkowski, Diversity and Motivation; Dorothy M. Steele and Becki Bohn-Vargas, Identity Safe Classrooms: Places to Belong and Learn (New York: Corwin Press, 2013). 
basic and even insulting questions about their country and culture. Creating space for students to share personal experience can deepen learning and student motivation to learn, e.g. 'did this passage resonate with any of you personally?' This is different from demanding a student share from personal experience or on behalf of a particular identity group, e.g. 'Sana, you are Pakistani - tell us what it is like to grow up female in a Muslim country?'

As a professor, you can set an inclusive tone by inviting everyone to share what they know about a given topic. In general, avoid 'tokenizing' students by expecting individual students to speak on behalf of an entire nation, region, race, or culture.

\section{7b. Avoid or Explain Culturally Specific References}

Having students from across the region and the world in your classes also means some references, words, and phrases that might be 'common knowledge' in your context will be foreign to others. For a British professor, illustrating a point by referencing 'the distance across The Channel', might be an obvious reference to the body of water between England and France. But students from other regions might wonder what you are talking about. Chanel, the fashion label? Or the waterway between Singapore and Malaysia? If you catch yourself using a reference or phrase that might be culturally contingent, take a minute to explain what you mean so all students get the benefit of the analogy or point you are trying to make.

\section{7c. Be Inclusive in Authors, References, and Illustrations}

You can contribute to a sense of belonging for students by assigning authors of different gender identities, case studies from a variety of regions, and scholarly perspectives that might be underrepresented in your discipline. If possible given your subjectmatter, use diverse examples and regional references in seminars and lectures. If broad representation is not an option in your discipline, acknowledge these imbalances to your students and invite critique. If an essential textbook only uses male pronouns, or if a historic document uses language which is considered derogatory and hateful in contemporary discourse, acknowledge this and give students an opportunity to discuss and process. If possible, show 
examples of scholars or other figures who can serve as role models to students from a variety of communities. Be conscious of how you use examples of historically marginalized peoples. For example, integrate examples of people in desirable roles and making leadership contributions, not only in positions of oppression and victimization that reinforce negative and demeaning stereotypes.

\section{Recognize Your Power}

You may not have pursued a career in academia in order to make students feel socially included, but that is a power you now have.

Faculty can help students feel included by accepting the leadership role they have in class. Students will look to professors for direction in difficult moments or when they feel alienated by something that happens in class. You can show you care and help maintain a productive learning environment by acknowledging difficult comments and following-up with impacted students outside of class when necessary. When a student makes an insulting or derogatory comment about traditionally marginalized communities, and a professor stays silent it can validate the ignorant comment. Silence by the professor harms the student who made the comment, as they miss the opportunity to become more reflective and inclusive communicators. Silence also harms students from marginalized identities, reinforcing feelings of vulnerability and exclusion.

In research on student perceptions of diversity and learning conducted at Yale-NUS College in Singapore, several students expressed a desire for faculty to be more assertive during class in addressing insensitive comments or stereotypes from fellow students. ${ }^{32}$ Some students from lessrepresented racial and ethnic groups shared that when faculty did not step in to correct unintentionally offensive statements, these minority students felt the weight of educating their peers about why those statements are offensive. This in turn distracts focus from the lesson at hand and makes minoritized students feel alienated in the class. Similarly, students who

\footnotetext{
32 Research conducted by Kristi Lemm and Joanna Lee for the Centre for Teaching and Learning at Yale-NUS College. Reported in "Early Experiences of Diversity in the YaleNUS Classroom," in Diversity and Inclusion in Curriculum and Classroom: A Community Resource for Yale-NUS Faculty and International Liberal Arts Educators (Singapore: YaleNUS College, 2019).
} 
represent minority gender and sexual identities can feel isolated and devalued when faculty do not step in to address a homophobic or transphobic comment, or do not use inclusive language around gender and sexuality themselves. Most students who voiced these concerns acknowledged that offensive comments were almost always unintentional. But faculty can still use their leadership role in the class to correct these unintended slights. ${ }^{33}$

While rooted in an American cultural context, the University of Michigan's Center for Research on Learning and Teaching and the Vanderbilt University Center for Teaching web sites have excellent, generalizable and practical resources to help faculty prepare to respond to difficult classroom situations or 'hot moments' inclusively and in ways that promote student learning. ${ }^{34}$

In diverse learning environments, with students and faculty of such varied backgrounds and identities, it is likely that someone will not realize that what they are saying is offensive or hurtful to those from different backgrounds. Faculty have power in the classroom and can enhance inclusion by taking responsibility for naming such comments, rather than expecting the most vulnerable and underrepresented students to educate and correct each other in these areas.

${ }^{33}$ For strategies for responding to difficult classroom situations or 'hot moments' the following research and resources are often transferable and valuable: Derald Sue, Annie Lin, Gina Torino, Christina Capodilupo, and David Rivera, "Racial Microaggressions and Difficult Dialogues on Race in the Classroom," Cultural Diversity and Ethnic Minority Psychology 15, no. 2 (2009): 183-190; Hanae Tsukada and Amy Perreault, "Complicating How Classroom Climate Works: Advancing the Framework," Transformative Dialogues: Teaching and Learning Journal 9, no. 2 (2016): 1-18; "Hot Moments," University of Michigan, accessed December 18, 2018, from www.crlt.umich.edu/category/tags/hotmoments; Penny Pasque, Mark Chesler, and Jessica Charbeneau, "Pedagogical Approaches to Student Racial Conflict in the Classroom," Journal of Diversity in Higher Education 6, no. 1 (2013): 1-16; Douglas Stone, Bruce Patton, and Sheila Heen, Difficult Conversation: How to Discuss What Matters Most (New York: Penguin, 1999).

${ }^{34}$ Visit "Responding to Difficult Moments," University of Michigan, www.crlt.umich. edu/multicultural-teaching/difficult-moments and "Difficult Dialogues," Vanderbilt University, https://cft.vanderbilt.edu/guides-sub-pages/difficult-dialogues/. On responding to difficult classroom situations see also Kay Landis, ed., Start Talking: A Handbook for Engaging in Difficult Dialogues (Anchorage: The University of Alaska Anchorage and Alaska Pacific University, 2008). 


\section{Conclusion: Reflect, LeARN, AND Listen}

This chapter has highlighted the value of proactively anticipating and incorporating students' diverse backgrounds and interests into pedagogy and course design. The techniques described here are drawn from the Inclusive Pedagogy and Universal Design for Learning approaches, which are designed to enhance belonging and learning for students in diverse higher education contexts.

Perhaps the best way to create an inclusive classroom is to be conscious and critical of your goals as an educator, and on any biases or blind spots you or your discipline may have that would pose barriers for learning in your classes. In particular, it is important to reflect on whether you have historically rewarded and favoured students who think like you, who share your learning or expression styles, and whether your pedagogy assumes students learn best the same way you do. These unconscious tendencies can disadvantage students with different learning needs and educational backgrounds. We have all been exposed to biases and stereotypes that may impact the way we see and operate in the world. The more we come to terms with those biases, the more we can work to prevent them from damaging our teaching. ${ }^{35}$

For example, reflect on whether you tend to call on particular students first, and why. The answer might be straightforward and simple: 'because those students always raise their hands first'. But consider why some students feel more comfortable or emboldened to speak than their peers. It might be because they come from cultures or education systems that emphasize speaking up during class. It might be because they hold privileged identities that empower them to speak, whereas other students have been exposed to subtle but consistent messaging that their voice is not welcome. As a teacher, you have the power to help other students find and use their voice. You can take steps to make speaking up during class more inclusive, and therefore more educationally impactful.

Ask yourself whether students of different genders and nationalities are contributing equally. If not, ask yourself if there is something you can do to invite all voices into the conversation-perhaps starting with group

${ }^{35}$ Mahzarin Banaji and Anthony Greenwald, Blindspot: Hidden Biases of Good People (New York: Delacorte Press, 2013); Claude Steele, Whistling Vivaldi: How Stereotypes Affect Us and What We Can Do (New York: W. W. Norton, 2011); James Jones, John Dovidio, and Deborah Vietze. The Psychology of Diversity: Beyond Prejudice and Racism (New York: Wiley, 2014). 
work, or assigning students specific speaking roles. One tool that might be helpful is to have your class videotaped, and then watch for gender, ethnic, or other dynamics at play in how you teach, and how students operate in the classroom. You can also ask someone to sit-in on your course with particular attention to inclusivity.

Soliciting input directly from students on whether they feel included and supported in the classroom is another powerful tool. The very act of asking is likely to make students feel valued, and motivated in your class. There are many options for this, including office hours, in-class conversations, mid-semester evaluations, and anonymous student feedback via online course management systems. For example, include a question on a mid-term feedback exercise like 'How comfortable do you feel participating in this class?' or 'How inclusive do you find our classroom dynamics to be with regard to nationality, gender, socio-economic background, and other forms of diversity?'

Knowing the popular discourses around diversity, inclusion, and education can also help you to anticipate students' desires and expectations. It is especially valuable to keep in contact with shifting generational discourses on these topics. Students are generally not experts in pedagogy, but they are experts in their own perceptions and personal experience of pedagogy. You may disagree with students about what constitutes desirable teaching or appropriate classroom behaviour, but it is still useful to understand their perspectives and perceived needs. You can monitor evolving ideas about teaching and learning by reading student newspapers, attending community dialogues and events, following the education section of your favourite journals and newspapers, participating in webinars or conferences through the education journals and associations in your area or discipline.

Cultivating an inclusive learning environment facilitates deeper student learning in many dimensions. Thoughtful reflection about where you are teaching, who you are teaching, and how you are teaching will help to harness student diversity for learning and avoid doing unintentional harm. As more research becomes available on mechanisms for inclusion across diverse higher education contexts in Asia, we will have more nuanced and contextual resources for inclusive teaching in the region.

Acknowledgements This chapter has benefited greatly from very thoughtful suggestions and encouragement from Brandon Yoder, Molly Scudder, Jacqueline Su, and Jennifer Silva. The chapter draws on faculty development resources produced at Yale-NUS College in collaboration with many colleagues, including Nancy Gleason, Joanna Lee, Lily Seah, Courtney Carter, Rachel Tan Wei Fen, 
Sahar Kazemini, Sara Amjad, and Matthew Stamps. I am indebted to many former and present mentors and colleagues at Yale-NUS College and the University of Virginia who fostered, deepened, and enabled my exploration into issues of academic inclusion and equity, including Deandra Little, Michael Palmer, Melissa Thomas-Hunt, Kyle Farley, Suyin Chew, Fiona Kanagasingam, Sara Amjad, D Dangaran, Jacqueline Su, Brian McAdoo, Joanne Roberts, and too many students to list by name. Thank you especially to Sara, D, Jackie, and Joanna for being particularly sage, humorous, and generous guides in helping me grapple with shifting expectations of higher education, the complex interplay of generation change, social justice, and academia, and to see the importance of faculty leadership regarding inclusion in the classroom and college.

\section{BIBLIOGRAPHY}

Almeida, Daniel J., Andrew M. Byrne, Rachel M. Smith, and Saul Ruiz. "How Relevant Is Grit? The Importance of Social Capital in First-Generation College Students' Academic Success." Journal of College Student Retention: Research, Theory \& Practice (2019).

Amador, José A., Libby Miles, and Calvin B. Peters. The Practice of ProblemBased Learning: A Guide to Implementing PBL in the College Classroom. New York: Jossey-Bass, 2006.

Arend, Bridget, and James R. Davis. Facilitating Seven Ways of Learning: A Resource for More Purposeful, Effective, and Enjoyable College Teaching. New York: Stylus, 2012.

Aronson, J., and M. Inzlicht. "The Ups and Downs of Attributional Ambiguity: Stereotype Vulnerability and the Academic Self-Knowledge of AfricanAmerican Students." Psychological Science 15, no. 12 (2004): 829-836.

Aronson, J., C. Fried, and C. Good. "Reducing the Effects of Stereotype Threat on African American College Students by Shaping Theories of Intelligence." Journal of Experimental Social Psychology 38 (2002): 113-125.

Aspelmeier, Jeffery E., Michael M. Love, Lauren A. McGill, Ann N. Elliott, and Thomas W. Pierce. "Self-Esteem, Locus of Control, College Adjustment, and GPA Among First- and Continuing-Generation Students: A Moderator Model of Generational Status." Research in Higher Education 53, no. 7 (2012): 755781 .

Bali, Maha, and Steve Greenlaw. "Tips for Inclusive Teaching." Chronicle of Higher Education, September 12, 2016. https://www.chronicle.com/blogs/ profhacker/tips-for-inclusive-teaching/62747.

Banaji, Mahzarin, and Anthony Greenwald. Blindspot: Hidden Biases of Good People. New York: Delacorte Press, 2013. 
Barr, Jason. "Developing a Positive Classroom Climate." Paper \#61, The IDEA Center, Miami, 2016.

Berrett, Dan. "The Unwritten Rules of College." The Chronicle of Higher Education, September 21, 2015. https://www.chronicle.com/article/TheUnwritten-Rules-of/233245.

Biggs, John. Teaching for Quality Learning at University. 2nd ed. Maidenhead: Open University Press, 2003.

Brabeck, Mary, Jill Jeffery, and Sara Fry. "Practice for Knowledge Acquisition (Not Drill and Kill).” Accessed December 18, 2018, from https://www.apa. org/education/k12/practice-acquisition.aspx.

Bracken, Sean, and Katie Novak, eds. Transforming Higher Education Through Universal Design for Learning: An International Perspective. Routledge: New York, 2019.

Bui, Dung C., and Mark A. McDaniel. "Enhancing Learning During Lecture Note-Taking Using Outlines and Illustrative Diagrams." Journal of Applied Research in Memory and Cognition 4, no. 2 (2015): 129-135.

Burgstahler, Sheryl E., ed. Universal Design in Higher Education: From Principles to Practice. 2nd ed. Cambridge: Harvard Education Press, 2015.

- "Universal Design of Instruction (UDI): Definition, Principles, Guidelines, and Examples." https://www.washington.edu/doit/universal-designinstruction-udi-definition-principles-guidelines-and-examples.

Carney, Russell N., and Joel R. Levin. "Pictorial Illustrations Still Improve Students' Learning from Text.” Educational Psychology Review 14, no. 1 (2002): $5-26$.

CAST. "CAST.” Accessed December 18, 2018, from www.cast.org.

—. "The UDL Guidelines.” udlguidelines.cast.org.

Coffield, F. D. Moseley, E. Hall, and K. Ecclestone. Learning Styles and Pedagogy in Post-16 Learning: A Systematic and Critical Review. London: Learning and Skills Research Centre, 2004.

Columbia University. "Guide to Inclusive Teaching at Columbia." Accessed December 18, 2018, from https://ctl.columbia.edu/resources-andtechnology/inclusive-teaching-guide/.

CRLT. "Examples of Discussion Guidelines." Accessed December 18, 2018, from http://www.crlt.umich.edu/examples-discussion-guidelines.

Davis, Barbara Gross. Tools for Teaching. 2nd ed. San Francisco: Wiley, 2009.

Deardorff, Darla K. "Assessing Intercultural Competence in Study Abroad Students." In Living and Studying Abroad: Research and Practice, edited by. Michael Bryam and Feng Anwei, 232-256. Clevedon: Multilingual Matters, 2006. 
Dedman, Ben. "For First-Generation Students, 'It's All About the Support You Have." Association of American Colleges and Universities, September 2017. https://www.aacu.org/aacu-news/newsletter/2017/september/ perspectives.

Dennis, Jessica M., Jean S. Phinney, and Lizette Ivy Chuateco. "The Role of Motivation, Parental Support, and Peer Support in the Academic Success of Ethnic Minority First-Generation College Students." Journal of College Student Development 46, no. 3 (2005): 223-236.

Duch, Barbara J., Susan E. Groh, and Deborah E. Allen, eds. The Power of Problem-Based Learning: A Practical "How To" for Teaching Undergraduate Courses in Any Discipline. New York: Stylus, 2001.

Dweck, Carol S. Mindset: The New Psychology of Success. New York: Ballantine Books, 2016.

Eberly Center. "Articulate Your Learning Objectives." Accessed December 18, 2018, from www.cmu.edu/teaching/designteach/design/learningobjectives. html.

Eddy, Sarah L., and Kelly A. Hogan. "Getting Under the Hood: How and for Whom Does Increasing Course Structure Work?” Life Sciences Education 13, no. 3 (2014): 453-468.

Elliott, Carole J., and Michael Reynolds. "Participative Pedagogies, Group Work and the International Classroom: An Account of Students' and Tutors' Experiences." Studies in Higher Education 39, no. 2 (2014): 307-320.

Florian, L., and K. Black-Hawkins. "Exploring Inclusive Pedagogy." British Educational Research Journal 37, no. 5 (2011): 813-828.

Fuertes, Jairo N., William E. Sedlacek, and William M. Liu. "Using the SAT and Noncognitive Variables to Predict the Grades and Retention of Asian American University Students." Measurement and Evaluation in Counseling and Development 27, no. 2 (1994): 74-84.

Galina, Ben. "Teaching First-Generation College Students." Accessed December 18, 2018, https://cft.vanderbilt.edu/guides-sub-pages/teaching-firstgeneration-college-students/.

Ginsberg, Margery, and Raymond Wlodkowski. Diversity and Motivation: Culturally Responsive Teaching in College. New York: Wiley, 2009.

Gurung, Regan, and Loraeto Prieto, eds. Getting Culture: Incorporating Diversity Across the Curriculum. New York: Stylus, 2009.

Hammer, Mitchell R. "The Intercultural Conflict Style Inventory: A Conceptual Framework and Measure of Intercultural Conflict Resolution Approaches." International Journal of Intercultural Relations 29, no. 6 (2005): 675-695.

Hausmann, L. R. M., J. W. Schofield, and R. L. Woods. "Sense of Belonging as a Predictor of Intentions to Persist Among African American and White First-Year College Students." Research in Higher Education 48, no. 7 (2007): 803-839. 
Higbee, Jeanne L., and Emily Goff, eds. Pedagogy and Student Services for Institutional Transformation: Implementing Universal Design in Higher Education. Minneapolis: University of Minnesota, 2008.

Hmelo-Silver, Cindy E. "Problem-Based Learning: What and How Do Students Learn?" Educational Psychology Review 16, no. 3 (2004): 235-266.

Hockings, Christine. "Inclusive Learning and Teaching in Higher Education: A Synthesis of Research." Accessed December 18, 2018, from https://www.heacademy.ac.uk/knowledge-hub/inclusive-learning-andteaching-higher-education-synthesis-research.

Hogan, Kelly, and Viji Sathy. "Structuring the Classroom for Inclusive Teaching." Accessed December 18, 2018, from https://cfe.unc.edu/initiatives/ structuring-the-classroom-for-inclusive-teaching/.

hooks, bell. Teaching Community: A Pedagogy of Hope. New York: Routledge, 2003.

Institute for Higher Education Policy. Supporting First-Generation Students Through Classroom-Based Practices. Washington, DC: Institute for Higher Education Policy, 2012.

Iowa State University. "Strategies to Create an Inclusive Course." Accessed December 18, 2018, from http://www.celt.iastate.edu/wp-content/ uploads/2015/10/StrategiestoCreateanInclusiveCourse.pdf.

John Bransford, Ann Brown, and Rodney Cocking, "How Experts Differ From Novices." In How People Learn: Brain, Mind, Experience, and School, edited by Ann Brown, Rodney Cocking, M. Suzzanne Donovan, and James W. Pellegrino, 31-50. Washington, DC: The National Academies Press, 2000.

Jones, James, John Dovidio, and Deborah Vietze. The Psychology of Diversity: Beyond Prejudice and Racism. New York: Wiley, 2014.

Kamenopoulou, Leda, ed. Inclusive Education and Disability in the Global South. New York: Palgrave, 2018.

Killick, David. Internationalization and Diversity in Higher Education: Implications for Teaching, Learning, and Assessment. New York: Palgrave, 2017.

Kolb, David A. Experiential Learning: Experience as the Source of Learning and Development. New York: Pearson, 1984.

Landis, Kay, ed., Start Talking: A Handbook for Engaging in Difficult Dialogues. Anchorage: The University of Alaska Anchorage and Alaska Pacific University, 2008.

Lang, James M. “A Welcoming Classroom.” September 27, 2017. https://www. chronicle.com/article/A-Welcoming-Classroom/241294.

- Small Teaching: Everyday Lessons from the Science of Learning. New York: Jossey-Bass, 2016.

Lee, Amy, Robert Roch, Marta Shaw, and Rhiannon Williams. Engaging Diversity in Undergraduate Classrooms: A Pedagogy of Developing Intercultural Competence. San Francisco: Wiley, 2012. 
Major, Claire Howell, Elizabeth F. Barkley, and K. Patricia Cross. Collaborative Learning Techniques: A Handbook for College Faculty. New York: Jossey-Bass, 2005.

McKeachie, Wilbert, and Marilla Svinicki. McKeachie's Teaching Tips. 14th ed. Belmont: Wadsworth Publishing, 2013.

McMurray, Andrew J., and Darrin Sorrells. "Bridging the Gap: Reaching FirstGeneration Students in the Classroom." Journal of Instructional Psychology 36, no. 3 (2009): 210-214.

Meyer, Erin. The Culture Map: Decoding How People Think, Lead, and Get Things Done Across Cultures. New York: PublicAffairs, 2015.

Michaelsen, Larry K., and Michael Sweet. "The Essential Elements of TeamBased Learning." New Directions for Teaching and Learning 2008, no. 116 (2008): 7-27.

Michaelsen, Larry K., Arletta Bauman Knight, L. Dee Fink, eds. Team-Based Learning: A Transformative Use of Small Groups in College Teaching. New York: Stylus, 2004.

Mitchell, Donald, Charlana Simmons, and Lindsay Greyerhiehl. Intersectionality and Higher Education: Theory, Research, and Praxis. New York: Peter Land Publishing, 2014.

Moallem, Isabel. "A Meta-Analysis of School Belonging and Academic Success and Persistence." PhD diss., Loyola University Chicago, 2013.

National Center on Universal Design for Learning. "UDL Center." Accessed December 18, 2018, from www.udlcenter.org.

Nguyen, Phuong-Mai. "Culturally Appropriate Pedagogy: The Case of Group Learning in a Confucian Heritage Culture Context." Intercultural Education 17, no. 1 (2006): 1-19.

Nguyen, Thai-Huy, and Bach Mai Dolly Nguyen. "Is the "First-Generation Student" Term Useful for Understanding Inequality? The Role of Intersectionality in Illuminating the Implications of an Accepted-Yet UnchallengedTerm." Review of Research in Education 42, no. 1 (2018): 146-176.

O'Keefe, Paul A., Carol S. Dweck, and Greg M. Walton. "Having a Growth Mindset Makes It Easier to Develop New Interests." Harvard Business Review, September 10, 2018. https://hbr.org/2018/09/having-a-growthmindset-makes-it-easier-to-develop-new-interests.

- "Implicit Theories of Interest: Finding Your Passion or Developing It?" Psychological Science 29, no. 10 (2018): 1653-1664.

Ostrove, Joan M., and Susan M. Long. "Social Class and Belonging: Implications for College Adjustment." The Review of Higher Education 30, no. 4 (2007): 363-389. 
Padgett, Ryan D., Megan P. Johnson, and Ernest T. Pascarella. "First-Generation Undergraduate Students and the Impacts of the First Year of College: Additional Evidence." Journal of College Student Development 53, no. 2 (2012): 243-266.

Pashler, Harold, Mark Mcdaniel, Doug Rohrer, and Robert Bjork. "Learning Styles: Concepts and Evidence." Psychological Science in the Public Interest 9, no. 3 (2008): 105-119.

Pasque, Penny, Mark Chesler, and Jessica Charbeneau. "Pedagogical Approaches to Student Racial Conflict in the Classroom." Journal of Diversity in Higher Education 6, no. 1 (2013): 1-16.

Persky, Adam, and Jennifer Robinson. "Moving form Novice to Experts and Its Implications for Instruction." American Journal of Pharmaceutical Education 81 , no. 9 (2017): 6065.

PERTS. “Teaching a Growth Mindset." Accessed December 18, 2018, from https://www.mindsetkit.org/topics/teaching-growth-mindset.

Pittman, Laura D., and Adeya Richmond. "Academic and Psychological Functioning in Late Adolescence: The Importance of School Belonging." The Journal of Experimental Education 75, no. 4 (2007): 270-290.

Ramburuth, Prem, and John McCormick. "Learning Diversity in Higher Education: A Comparative Study of Asian International and Australian Students." Higher Education 42, no. 3 (2001): 333-350.

Ramey, Jessy. "12 Evidence Based Teaching Strategies to Create a Productive and Inclusive Classroom Climate." Accessed December 18, 2018, from https://my.chatham.edu/documents/documentcenter/12\%20Evidence $\%$ 20Based $\% 20$ Teaching $\% 20$ Strategies $\% 20$ to $\% 20$ Create $\% 20$ Productive $\% 20$ and $\%$ 20Inclusive $\% 20$ Classroom\%20Climate\%20.pdf.

Richardson, R., and E. Skinner. "Helping First-Generation Minority Students Achieve Degrees." New Directions for Community Colleges 1992, no. 80 (1992): 29-43.

Rolls, Nicolla, Andrew Norhedge, and Ellie Chambers, eds. Successful University Teaching in Times of Diversity. New York: Palgrave Teaching and Learning, 2018.

Rose, David, Wendy Harbour, Catherine Johnston, Samantha Daley, and Linda Abarbanell. "Universal Design for Postsecondary Education: Reflections on Principles and Their Application." Journal of Postsecondary Education and Disability 19, no. 2 (2004): 135-151.

Saunders, Shari, and Diana Kardia. Creating Inclusive College Classrooms. Ann Arbor: University of Michigan, 1994.

Savery, John R. "Overview of Problem-Based Learning: Definition and Distinctions." The Interdisciplinary Journal of Problem-Based Learning 1, no. 1 (2006): 9-20. 
Sellers, Sherrill, Jean Roberts, Levi Giovanetto, Katherine Friedrich, and Caroline Hammargren. Reaching All Students: A Resource for Teaching in STEM. 2nd ed. Madison: CIRTL, 2007.

Sharan, Yael. "Cooperative Learning: A Diversified Pedagogy for Diverse Classrooms." Intercultural Education 21, no. 3 (2010): 195-203.

Spencer, S. J., C. M. Steele, and D. M. Quinn. "Stereotype Threat and Women's Math Performance." Journal of Experimental Social Psychology 35 (1999): 428.

Steele, Claude. Whistling Vivaldi: How Stereotypes Affect Us and What We Can Do. New York: W. W. Norton, 2011.

Steele, Dorothy M., and Becki Bohn-Vargas. Identity Safe Classrooms: Places to Belong and Learn. New York: Corwin Press, 2013.

Stephens, Nicole M., Stephanie A. Fryberg, Hazel Rose Markus, Camille S. Johnson, Rebecca Covarrubias. "Unseen Disadvantage: How American Universities' Focus on Independence Undermines the Academic Performance of First-Generation College Students." Journal of Personality and Social Psychology 102, no. 6 (2012): 1178-1197;

Stevens, Dannelle, and Antonia Levi. Introduction to Rubrics: An Assessment Tool to Save Grading Time, Convey Effective Feedback, and Promote Student Learning. New York: Stylus, 2013.

Stone, Douglas, Bruce Patton, and Sheila Heen. Difficult Conversation: How to Discuss What Matters Most. New York: Penguin, 1999.

Strayhorn, Terrell L. College Students' Sense of Belonging: A Key to Educational Success for All Students. 2nd ed. New York: Routledge, 2018.

- "Factors Influencing the Academic Achievement of First-Generation College Students." NASPA Journal 43, no. 2 (2006): 82-111.

Sue, Derald, Annie Lin, Gina Torino, Christina Capodilupo, and David Rivera. "Racial Microaggressions and Difficult Dialogues on Race in the Classroom." Cultural Diversity and Ethnic Minority Psychology 15, no. 2 (2009): 183-190.

Suskie, Linda. Assessing Student Learning: A Common Sense Guide. New York: Wiley, 2018.

Terada, Youki. "Multiple Intelligences Theory: Widely Used, Yet Misunderstood." October 15, 2018. https://www.edutopia.org/article/multipleintelligences-theory-widely-used-yet-misunderstood.

The Digital Library Federation. "Guide to Creating Accessible Presentations." Accessed December 18, 2018, from www.diglib.org/forums/2016forum/ guide-to-creating-accessible-presentations/.

Ting-Toomey, Stella, and Leeva C. Chung. Understanding Intercultural Communication. 2nd ed. Oxford: Oxford University Press, 2011.

Tobin, Thomas J., and Kirsten T. Behling. Reach Everyone, Teach Everyone: Universal Design for Learning in Higher Education. West Virginia University Press, 2018. 
Tracey, Terence J., and William E. Sedlacek. "Prediction of College Graduation from Noncognitive Variables by Race." Measurement and Evaluation in Counseling and Development 19, no. 4 (1987): 177-184.

Tsukada, Hanae, and Amy Perreault, "Complicating How Classroom Climate Works: Advancing the Framework." Transformative Dialogues: Teaching and Learning Journal 9, no. 2 (2016): 1-18.

Universal Design for Higher Learning in Education. "UDL on Campus." udloncampus.cast.org.

University of Colorado. "First Generation College Students." Accessed December 18, 2018, from http://www.ucdenver.edu/faculty_staff/faculty/centerfor-faculty-development/resources/Teaching\%20resources/firstgen/Pages / default.aspx.

University of Michigan. "Hot Moments." Accessed December 18, 2018, from www.crlt.umich.edu/category/tags/hot-moments.

—. "Responding to Difficult Moments." www.crlt.umich.edu/multiculturalteaching/difficult-moments.

University of Washington in St. Louis. "Facilitating Challenging Conversations in the Classroom." Accessed December 18, 2018, from https:// teachingcenter.wustl.edu/resources/inclusive-teaching-learning/facilitatingchallenging-conversations-in-the-classroom/.

-. "Using Roles in Group Work." Accessed December 18, 2018, from http://teachingcenter.wustl.edu/resources/teaching-methods/groupwork-in-class/using-roles-in-group-work/.

van Kesteren, Marlieke, Mark Rijpkema, Dirk J. Ruiter, Richard G. M. Morris, and Guillén Fernández. "Building on Prior Knowledge: Schema-Dependent Encoding Processes Relate to Academic Performance." Journal of Cognitive Neuroscience 26, no. 10 (2014): 2250-2261.

Vanderbilt University. "Difficult Dialogues.” https://cft.vanderbilt.edu/guidessub-pages/difficult-dialogues/.

—. "Teaching Problem Solving." Accessed December 18, 2018, from https://cft.vanderbilt.edu/guides-sub-pages/problem-solving/.

"Web Accessibility Initiative." Accessed December 18, 2018, from www.w3.org.

Weimer, Maryellen. Learner-Centered Teaching: Five Key Changes to Practice. New York: Jossey-Bass, 2013.

Williams, Damon. Strategic Diversity Leadership: Activating Change and Transformation in Higher Education. Sterling: Stylus, 2013.

Yale-NUS College. Diversity and Inclusion in Curriculum and Classroom: $A$ Community Resource for Yale-NUS Faculty and International Liberal Arts Educators. Singapore: Yale-NUS College, 2019.

Yi, P. "Institutional Climate and Student Departure: A Multinomial Multilevel Modeling Approach." Review of Higher Education 31, no. 2 (2008): 161183. 
Yorks, Jessica. "When Parents Can't Help: How Can We Support FirstGeneration College Students?" April 23, 2018, https://gcci.uconn.edu/ 2018/04/23/when-parents-cant-help-how-can-we-support-first-generationcollege-students/\#.

Zhao, Chun-Mei, and George D. Kuh. "Adding Value: Learning Communities and Student Engagement." Research in Higher Education 45, no. 2 (2004): $115-138$.

Open Access This chapter is licensed under the terms of the Creative Commons Attribution 4.0 International License (http://creativecommons.org/licenses/ by $/ 4.0 /)$, which permits use, sharing, adaptation, distribution and reproduction in any medium or format, as long as you give appropriate credit to the original author(s) and the source, provide a link to the Creative Commons license and indicate if changes were made.

The images or other third party material in this chapter are included in the chapter's Creative Commons license, unless indicated otherwise in a credit line to the material. If material is not included in the chapter's Creative Commons license and your intended use is not permitted by statutory regulation or exceeds the permitted use, you will need to obtain permission directly from the copyright holder.

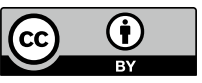

